\title{
InkBlog: A Pen-Based Blog Tool for e-Learning Environments
}

\author{
André Constantino da Silva \\ Instituto Federal de São Paulo, \\ Hortolândia, São Paulo, Brazil \\ CPG-IC, State University of \\ Campinas, Campinas, \\ São Paulo, Brazil
} andre.constantino@ifsp.edu.br

\author{
Heloísa Vieira da Rocha \\ IC - NIED, \\ State University of Campinas, \\ Campinas, \\ São Paulo, Brazil
}

heloisa@ic.unicamp.br

\begin{abstract}
Weblogs are communication and collaborative tools disposed in Web that aims to publish texts and sharing opinions, typically displaying the post in reverse chronological order, and allowing visitors to leave comments. Since devices equipped with pen are becoming common, such as tablets, and have enough computational power to render Web pages, users can access blog tools through pen-based devices, writing new posts and read and comment published posts. But tablets have a different input style and the user need to type the post instead of handwriting it, decreasing the usability and make boring the writing task in these devices. Pen-based computing refers to a computer user-interface using a pen, rather than devices such as a keyboard or a mouse, and is a promise research area to enhance Education, but it is need to properly consider the pen. We purpose the InkBlog, a blog tool that receive input data from pen so that the user can handwriting her posts. In this work we present the InkBlog architecture and the main component, the InkEditor for Web pages. Using InkBlog the user can write equations or sketches faster than using a mouse or a keyboard, getting the best of the pen-based devices.
\end{abstract}

Keywords: pen-based interaction, e-Learning environments, user interface design, usability.

\section{Introduction}

Blog software is a communication and collaborative tool disposed in Web that aims to promote the sharing of messages among participants through an area named blog. Users can publish texts, images, audio, videos and links and sharing opinions in posts typically displayed in reverse chronological order (the most recent post appears first) and allowing visitors to leave comments. In this way, blogging can be seen as a form of social networking.

Material published as part of this publication, either on-line or in print, is copyrighted by the Informing Science Institute. Permission to make digital or paper copy of part or all of these works for personal or classroom use is granted without fee provided that the copies are not made or distributed for profit or commercial advantage AND that copies 1) bear this notice in full and 2) give the full citation on the first page. It is permissible to abstract these works so long as credit is given. To copy in all other cases or to republish or to post on a server or to redistribute to lists requires specific permission and payment of a fee. Contact Publisher@InformingScience.org to request redistribution permission.
In education, blogs can be used as instructional resources, referred to as edublogs. Edublogs archive and support student and teacher learning by facilitating reflection, questioning by self and others, collaboration (Ray, 2006) and by providing contexts for engaging in higher-order thinking. Ray (2006) cites four ways to incorporate blogs into the classroom, including: (i) using them to communicate information to students and 
parents; (ii) to provide instructional resources and useful links; (iii) to allow students the opportunity to collaborate with one another on various projects without being in the classroom itself; and (iv) to showcase student work and projects, like poetry and photographs of project work.

In e-Learning environments, each course participant (student or teacher) owns a blog, where she can post or exclude messages. Each participant may access other course participants' blogs, comment posted messages by the owner of the blog. In Weblogs, to write a post, the users interact with in a text editor that allows users without HTML (HyperText Markup Language) skills to write rich text.

Mobile devices, such as smartphones and tablets, are becoming increasingly popular; most of them have touch screen displays, Internet access and enough computing power to process Web pages. So it is possible to access Weblogs, read the messages, post new messages and write comments. But it is important consider that these pages are developed to be used with keyboard, mouse and a medium size display, and the changing of interaction styles brings interaction problems (da Silva, Freire, \& da Rocha, 2013) and does not take advantages of the interaction style features. For example, to post a message in a Weblog using a pen-based device the user needs to type each letter pressing the respective key in a virtual keyboard. This way of writing the text take a lot of time, make boring the writing task and do not take the mainly pen purpose: handwriting and do sketches easily.

We believe that the e-learning environment needs to be improved to be more easy to use in some contexts, e.g., areas which need sketches or drawing such Mathematics. To make it easier to handwrite or sketched posts in pen-based devices, we add features to manipulate electronic ink into a blog tool and called InkBlog. This work describes the InkBlog tool and presents some uses in e-Learning. The next Section presents a literature review about electronic ink technology, the e-Learning environments focusing in Weblog. The following Section presents the InkBlog, describing how the technologies are employed to allow users handwriting posts and comments. The last Section presents the conclusion and future works.

\section{Literature Review}

The recent technology forwards brings a broad of new applications made to support many areas, such Education. One of the mobile devices that are gained repercussion in this scenario is the Tablet PC (Tablet Personal Computer), a device with height as similar to a notebook and had an input device similar a pen. The paper and pen metaphor implies that tasks performed before in paper, like draw or manuscript writing, can be more natural in the Tablet PC than in the another computing devices. Resuming, the Tablet PC has the following hardware characteristics: (i) Pen sensitive screen; (ii) Screen that allow different positions; (iii) Wireless network access by WLAN (Wireless Local Area Network) and bluetooth technology; (iv) Microphones and embedded loudspeakers; (v) Keyboard (some models the keyboard are detachable); (vi) Batteries.

Pen-based Computing or Pen Computing refers to a computer user-interface using a pen, rather than devices such as a keyboard or a mouse. User interfaces for pen computing can be implemented in several ways, like using the pen as a pointing input device, but takes better advantages when the application is developed considering direct manipulation, handwriting or gesture recognition. Educational applications for contexts where paper and pen usually are presents can benefits from this new interaction style and from pen-based computing, offering better experiences of use for teachers and students.

Berque, Bonebright and Whitesell (2004) describes the use of pen-based electronic classrooms covering topics from the undergraduate computer science curriculum such as two-dimensional arrays, pointer-based linked lists, binary search trees, directed and undirected graphs, digital logic diagrams, and finite state automata. The authors say that these concepts are very difficult to 
communicate quickly and extemporaneously using a keyboard and they are also difficult to describe orally, studying the use of Tablet PC to cover these topics. Through a questionnaire, they conclude that pen-based computers are well-received in the Computer Science classroom.

Florea and Radu (2007) present a study using the pen-based technology to improve the quality and efficiency of the instructional process in a computer science course using concept maps, showing how the pen-based technology can support several learning styles. They developed the Pen Annotator, a tool to do graphical annotation on documents, and @Graph, a tool to develop and manage concept maps. Classroom Presenter (Anderson et al., 2007) is a Tablet PC-based classroom interaction system that supports the sharing of digital ink on slides between instructors and students to increase the instructor's flexibility while lecturing.

Benlloch, Buendía and Cano (2009), using the Classroom Presenter, discuss an approach with six steps based on a teaching method that incorporates active learning techniques and supports inclass teacher/student and student/student collaborations. They implemented in a first-year Computer Engineering Course, using a wireless classroom equipped with 25 Tablet PCs for students and one additional for the instructor, which is connected to the data projector. Benlloch, Buendía and Cano (2009) propose sketching in the early stages of project-based approaches using Tablet PCs and polls to gather formative information and in turn providing immediate feedback, activities supported by Classroom Presenter.

Pargas et al. (2007) presents a Tablet PC application, called OrganicPad, which enable an instructor to engage her students in class by sending them Chemistry problems to solve. The students develop answers to the problems guided by tips and hints provided by the software. Labahn et al. (2008) propose MathBrush, a tool that allows users to draw math input using a pen-input device on a tablet computer, recognizes the math expression, and then supports mathematical transformation and problem solving. The authors argue that entering mathematics on a computer is problematic, it is more natural write the formulae than inputting the latex form, maple form or mathematic form.

McCormick (2007) points out that, based on a study with primary (3-11 years) classrooms in the United Kingdom, a high degree of interaction and collaboration and a greater ownership over their work when use interactive whiteboards and other pen-based learning technologies on pedagogical practice. Backon (2006) says that the keyboard allows a rapid typewriting and do texts structured by topics, but only pen can allow a creativity increment, better flexibility and a natural record of the think development process and rationale in all stages (ideal requirements for the educational environment), aging like a direct hand extension. For example in the resolution of complex problems with a large calculus solution, by using applications is possible to record all the steps and draw diagrams that explain the problem resolution, step by step.

When the user moves the pen in the screen, the pen trace should result in electronic ink that must be treated by the application to be rendered and stored. But desktop applications, that running in the Tablet PCs, do not treat electronic ink, so it is necessary special applications to treat the electronic ink to have benefices of the pen interaction style. This is the case of Classroom Presenter and the other described pen-based software. In our previous work (da Silva \& da Rocha, 2012) we studied three applications (Professional Adobe Acrobat, Windows Journal and Jarnal) for do classes annotations or writing manuscript in student activities using a Tablet PC, describing some identified usability problems. Desktop applications do not manipulate the electronic ink, resulting in loose of the Tablet PC potential because the pen is used only as a pointer device. In this case, the use of pen as a pointer device in desktop applications brings some usability problems, such the difficult to see the content when the user needs to cross the screen with her hand. There is similar lack of technologies too in web browsers, and since pen based devices has computational power enough to render Web pages, there is a need to fill these gap. 
InkBlog: A Pen-Based Blog Tool for e-Learning Environments

The World Wide Web has changed since its invention from a static to a highly dynamic media in the recent years, so the term "Web 2.0" was coined in 1999 to describe web sites that use technology beyond the static pages and its uses for collaborative, user-centric content production and interactive content access (O'Reilly, 2005). Safran, Helic and Gütl (2007) describe that in literature the marks of Web 2.0 includes (1) social phenomena such as the Web for participation, (2) technology for significant change in web usage, and (3) design guidelines for loosely coupled services. The Web 2.0 allows users to interact and collaborate with each other in social networking sites, weblogs, podcasts, wikis, video sharing sites and other sort of tools.

One kind of Web applications is e-Learning environments, as Moodle (http://moodle.org), SAKAI (http://sakaiproject.org) and Ae (http://tidia-ae.iv.org.br/), applications with tools to support teaching and learning activities though the Web and have some Web 2.0 characteristics. Tools in these environments allow users to create content, communicate with other users and manage the virtual space. Tools like chat, forums, portfolios, repositories are widely used, and tools that explore the audio and video resource to user communication, such as instant messenger and videoconferences, are becoming common among the environments. These environments take advantages of the Web to offer content with text, images, audios and videos in a hypertext document.

The mainly Web technology, the HTML, evolved too and the improvement defined to the last version, the HTML5, are related with support multimedia, keep it easily readable by humans and consistently understood by computers and devices (Berjon et al., 2012). HTML5 adds the new $<$ video $>$, < audio $>$ and $<$ canvas $>$ tag elements, as well as the integration of Scalable Vector Graphics (SVG, a vector image format for two-dimensional graphics based on eXtended Markup Language - XML) content and MathML (Mathematical Markup Language is a XML basedformat to describing mathematical notations) to integrate mathematical formulae into Web pages. These features are designed to make it easy to include and handle multimedia and graphical content on the web without having proprietary plugins and APIs (Application Programming Interface) installed.

The $<$ canvas $>$ tag allows for dynamic, scriptable rendering of 2D shapes and bitmap images, allowing a drawable region defined in HTML code with height and width attributes. JavaScript code may access the area through a full set of drawing functions similar to those of other common 2D APIs, thus allowing for dynamically generated graphics.

W3C, the World Wide Web Consortium who standardizes HTML, defines XML formats for nonprimitive data to allow exchange of a wide variety of data on the Web and elsewhere, and one example is InkML (Chee et al., 2011). The InkML (Ink Markup Language) provides a common format for the exchange of ink data between components such as handwriting and gesture recognizers, signature verifiers, sketches, music and other notational languages in applications. The InkML serves as the data format for representing ink entered with an electronic pen or stylus. It is possible to find some uses of InkML, such in Microsoft Word 2010 support electronic ink in text review and the InkML JavaScript Library (http://inkml.codeplex.com/), that offers some functions to allows InkML digital ink to be referenced within Web pages and rendered directly into the HTML5 < canvas $>$ tag.

Considering the technology breakthrough that HTML5 purposes, most of the web sites uses HTML5 to impress the user in the content exhibition and few take care about the user input interaction styles, developing the web pages considering the user is interacting with keyboard and mouse in desktop computers. But this scenario is changing with the smartphone and tablet popularization: the web designers need to think about the other interaction styles, such as touchscreen and pen-sensitive devices. 
Another characteristic of Web 2.0 is that they would be used by a variety of devices and platforms. Devices have Internet access and have enough computing power to render Web pages and using good practices to design Web pages is possible to render in small devices. But some devices have interaction hardware different from desktops; some have touchscreen and other pensensitive screen, such Tablet PCs.

Berque, Bonebright and Whitesell (2004), Florea and Radu (2007), Anderson et al. (2007), McCormick (2007), Benlloch, Buendía and Cano (2009) points out benefits in using Tablet PC in classrooms. These works and da Silva and da Rocha (2011) studied the use of Tablet PC in teaching or learning activities in or out classrooms in presence courses. But how to get the pen computing advantages in Web tools, mainly in e-Learning environments? Users with pen-based devices, such as tablet, can access Weblogs and easily read the posts, but writing blog post is not too easy: the user needs to type the text; even she is using a pen. To make it easier to handwrite posts and allow users post sketches in pen-based devices, we add features based on HTML5 technologies to manipulate electronic ink into a blog tool and called InkBlog. The remainder of this section presents the Ae environment and its Weblog tool, the software we used as base to create the InkBlog.

\section{Ae Environment}

The TIDIA-Ae Project (TIDIA-Ae is the acronym for "Tecnologia da Informação para o Desenvolvimento da Internet Avançada - Aprendizado Eletrônico", in English "Information Technology for Development of Advanced Internet - Electronic Learning") was initiated by FAPESP (the State of São Paulo Research Foundation) with the main goal of developing an e-Learning environment that can explore the potential of Advanced Internet and can provide support to different educational context needs. To provide a flexible system the Ae project defined a layered component-based architecture for Ae environment. The advantages of using component-based software architecture, and which justify its adoption, are related to the following characteristics that are obtained:

(i) Abstraction: explicit separation between the specification and the implementation of functionalities; and

(ii) Uniform composition: in order to assemble functionalities implemented by distinct components, there must be communication between these components' provided and required interfaces, thereby providing uniform composition. In this way, it is possible to reuse components (Reusability) developed by other educational institutions, bringing increased productivity and quality of the produced software.

Layered component-based software architecture was defined for the TIDIA-Ae Project (Beder, Casagrande, \& Rubira, 2004) with the following layers:

- Presentation layer: provides the application user interface;

- System layer: provides an interface for the application functionality;

- E-Learning layer: provides the component interfaces that implement the application's business rules, which can be used by various applications;

- Infrastructure layer: implements a set of infrastructure services such as, for example, data persistence;

- Common services layer: has the public services that can be utilized and accessed by all other architecture layers, except the presentation layer.

Following this architecture the Ae project developed a set of tool that was integrated with Sakai environment nucleus to compose the Ae environment. One Ae's tool is Weblog, an edublog tool. The next session explain its purpose and its architecture. 


\section{The Weblog Tool}

The Weblog tool makes possible to the user share with other participants texts, video or audio messages. The posted messages may be commented by the readers of the Weblog. Each participant (student or teacher) has a blog are for each course (Figure 1). The participant can post messages in her blog, clicking in the link "Compose a new post" in the user blog page. A page within a form to be filled will be displayed (Figure 2). After fill up the form, the user click in the "Confirm" button and the system will redirect the user to the user blog page displaying the new message at top.

The user can read messages posted by other participants accessing the participant's blog, and comment the message posted by other participants in their blog area clicking in the link "Post a comment". The system will display a form to be filled in a new window (Figure 3), and to submit the new comment the user needs to click in the "Confirm" button. The new comment will be displayed when the user will click in the "Show comments" link next to the commented message.

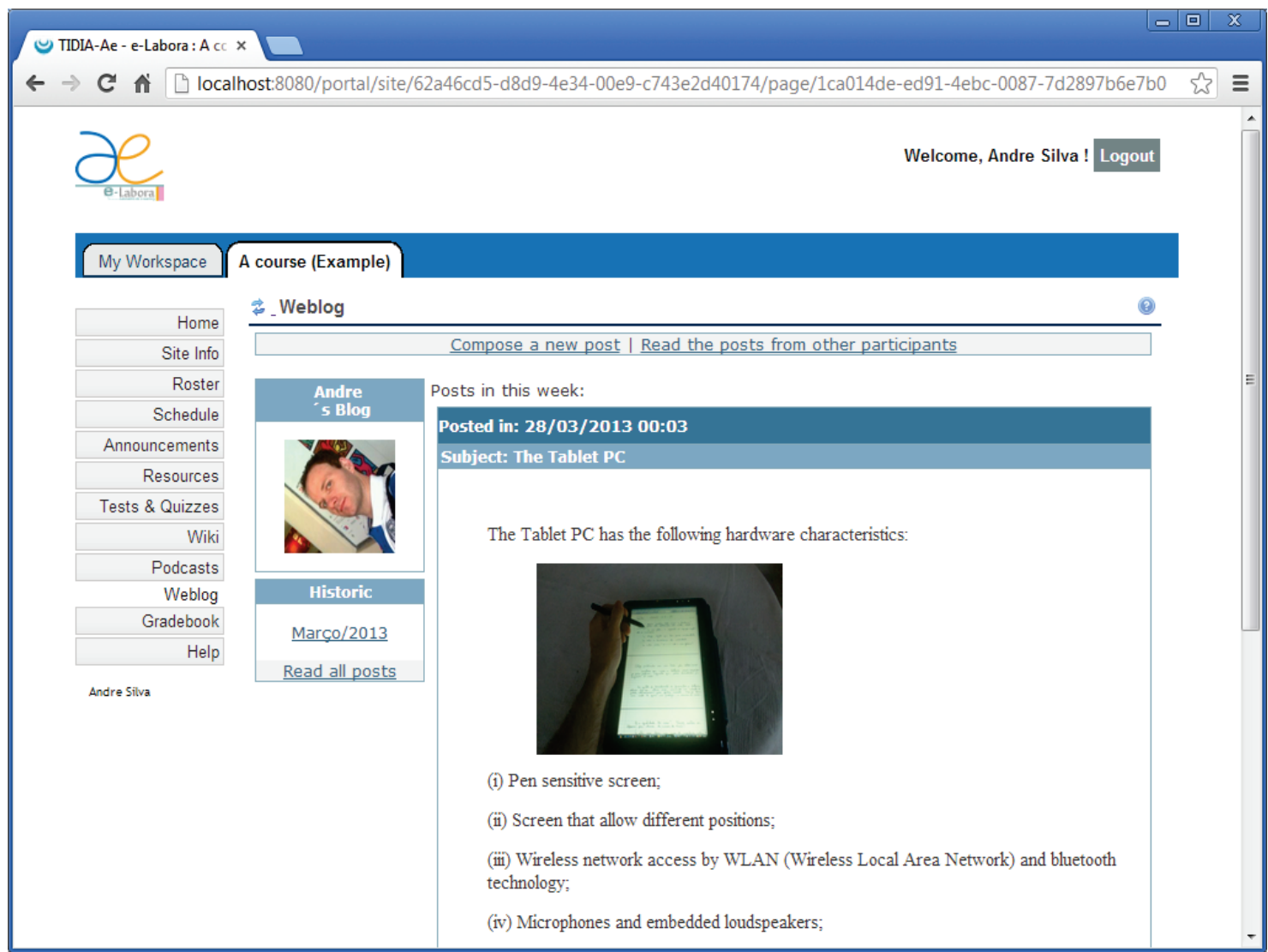

Figure 1: A participant weblog area in Ae's Weblog tool rendered by Google Chrome.

Weblog tool was developed following the Ae architecture and developing platform (Beder et al., 2007), described in the above Section, and its presentation layer was codified using Struts and Tiles (da Silva et al., 2006). Struts is a framework to extends the Java language to develop software based on a Model-View-Controller (MVC) architecture and Tiles is a template mechanism that allows the presentation layer to be composed from independent header, footer, and content components making more easy develop Web pages avoiding code replication. 


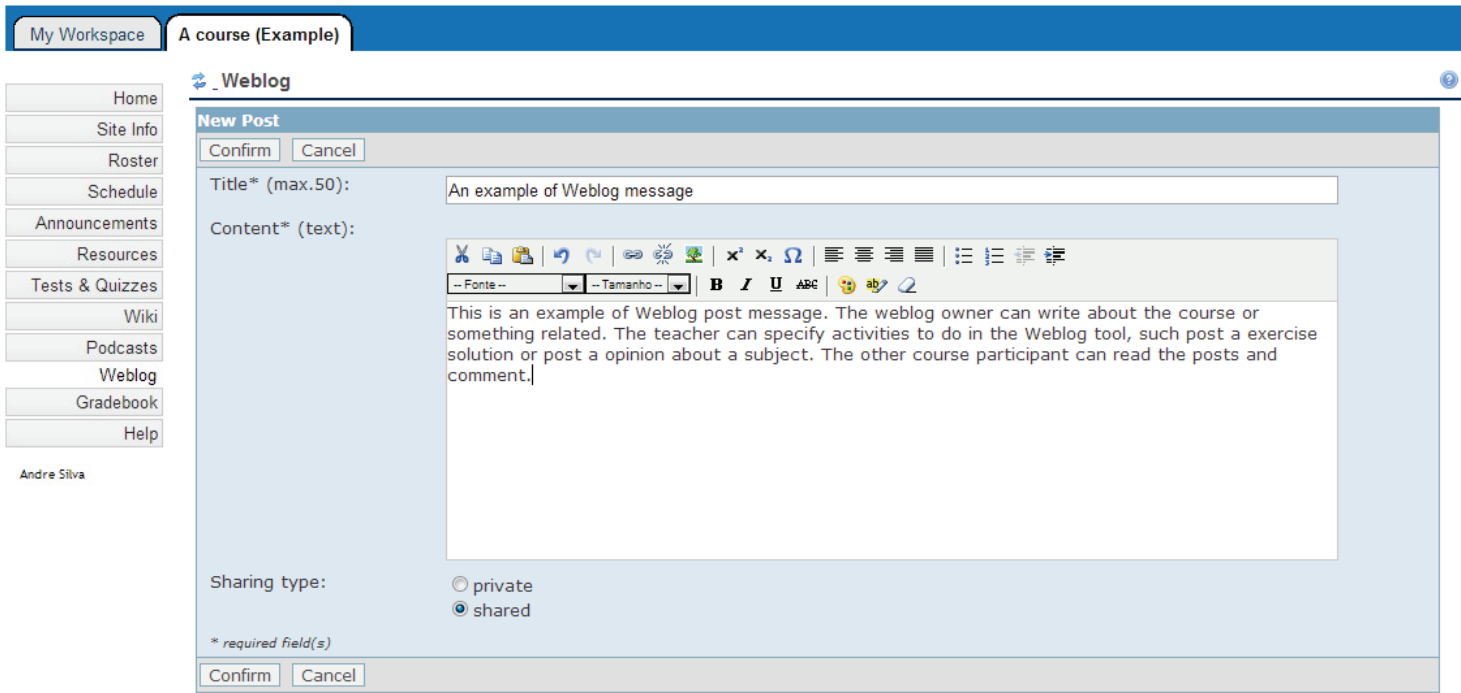

Figure 2: User posting a new message in her weblog.

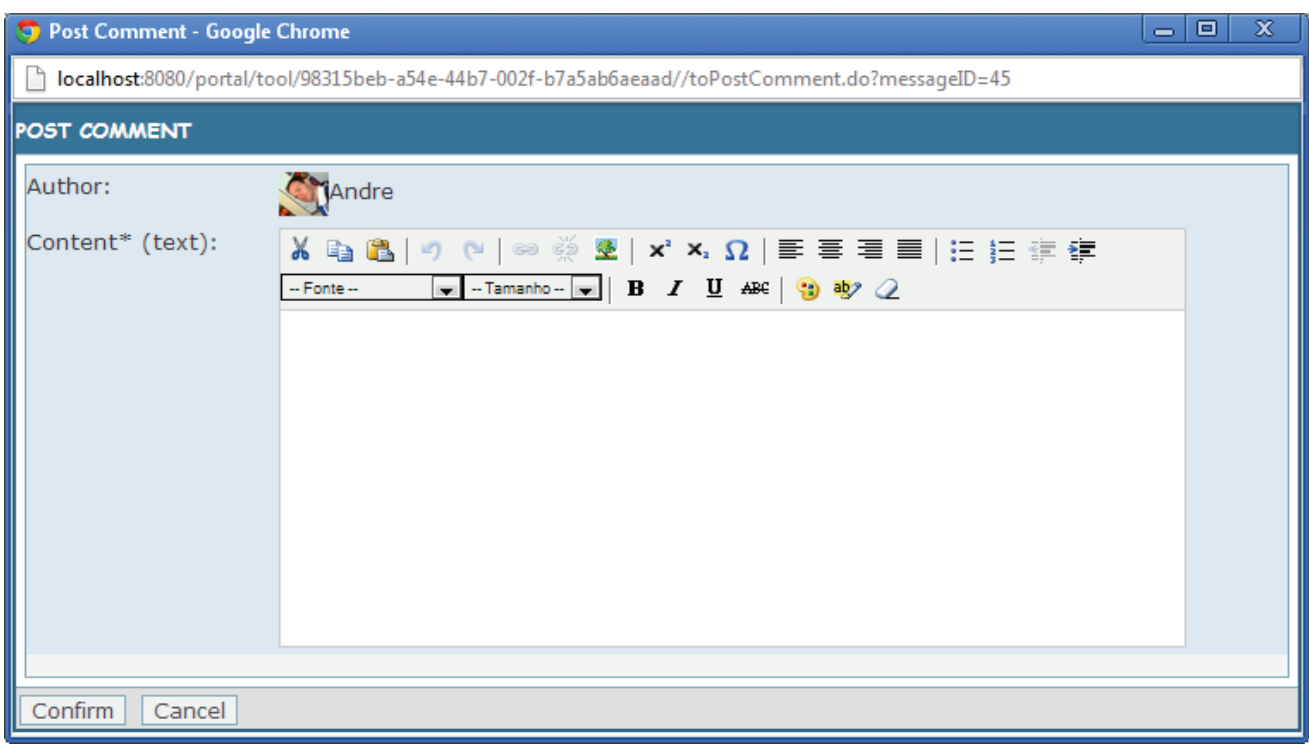

Figure 3: A participant writing a comment for a posted message in other participant weblog area.

\section{The Weblog Tool Architecture}

This section presents the results from the phase of mapping the software components of the Web$\log$ tool onto the architecture defined by the TIDIA-Ae project. Figure 4 presents the components responsible for the implementation of the functionalities of this tool distributed in the layers defined by the Ae architecture. 


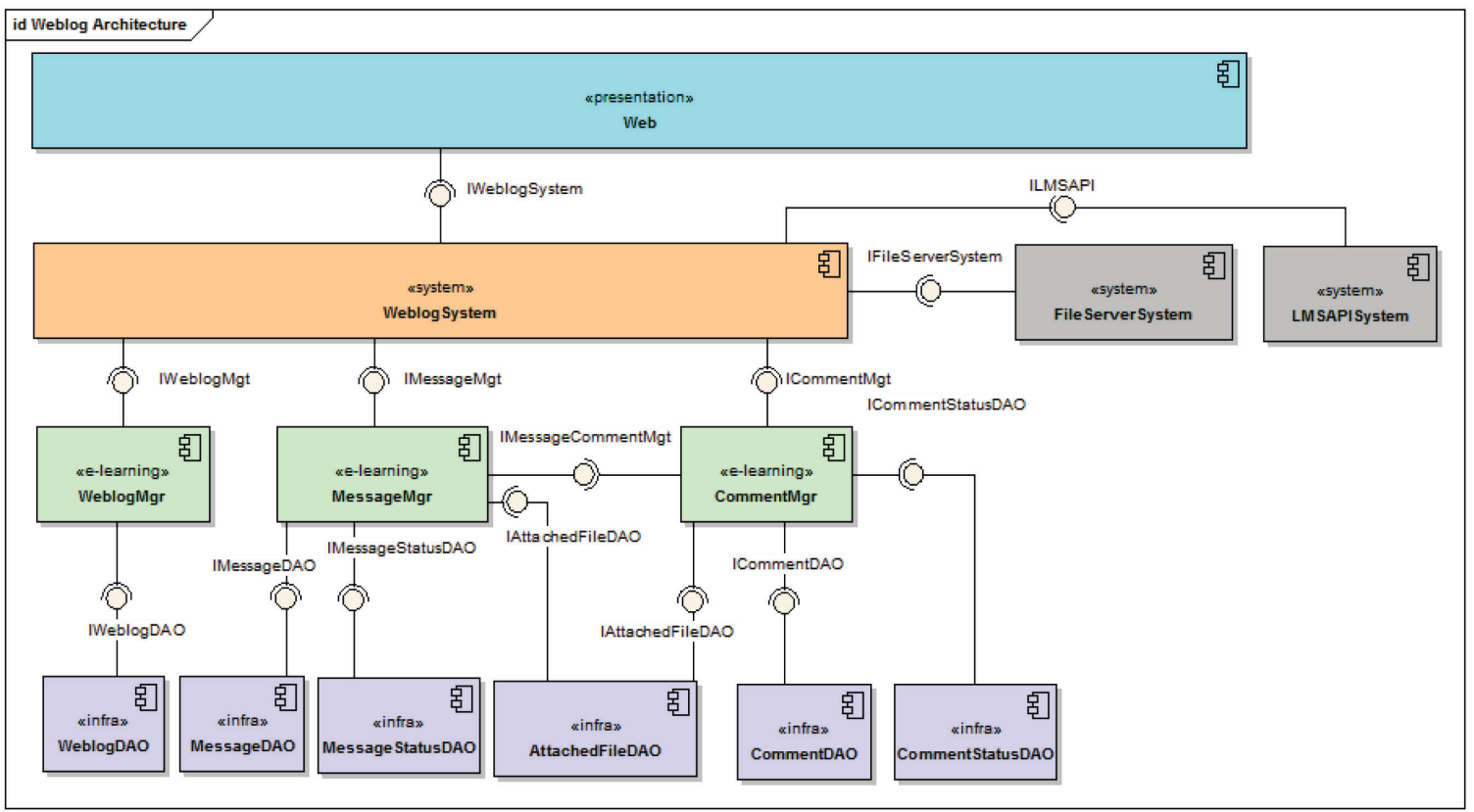

Figure 4: Weblog Tool Components.

We used J2EE (Java Enterprise Edition, an API and runtime environment for developing and running enterprise software in Java language) as the development platform in the implementation of the Ae tools. In relation to this technology, the following decisions were taken:

- Tomcat (http://tomcat.apache.org) as the J2EE application server;

- Java Beans were used in the system and e-learning layers according to the decisions of the TIDIA-Ae Architecture Group;

- Hibernate (http://www.hibernate.org) was also adopted as the main persistence framework.

\section{The InkBlog Tool}

The InkBlog was created to make it easier to handwrite posts and comments using pen. We increased the Weblog tool with components to generate and manipulate the electronic ink in the user interface, representing the electronic ink in InkML format. Figure 5 shows the InkBlog architecture, based on Weblog architecture. The client device needs to have a compatible HTML5 browser to run the InkEditor, a user interface component that will render the electronic ink and

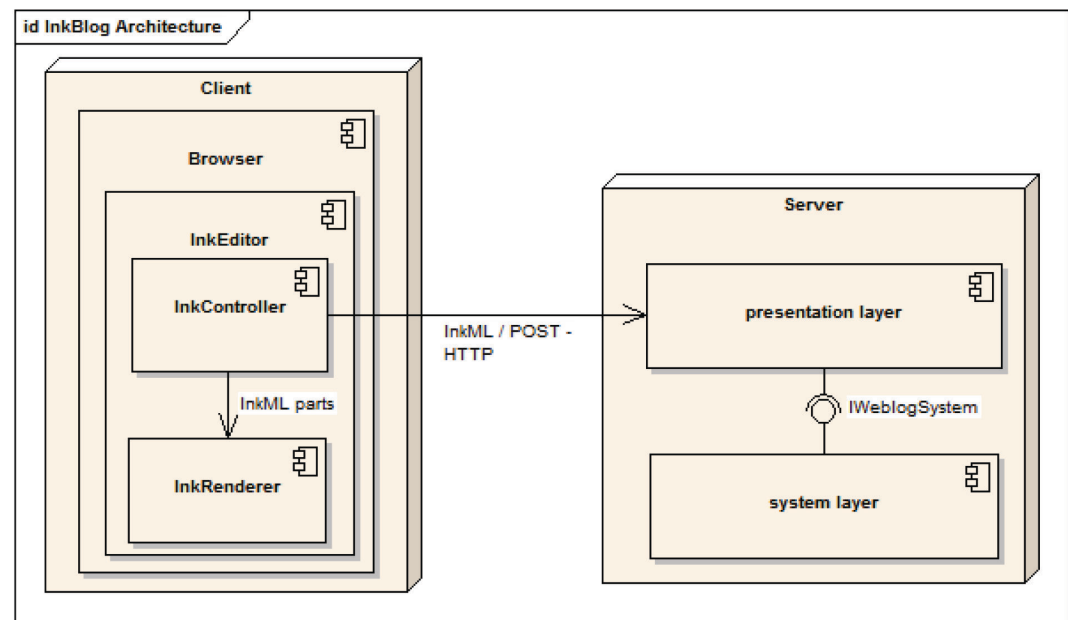

Figure 5: InkBlog Tool Components used in a handwritten or sketched post. 
will receive the input data generated by the pen. The InkEditor uses InkML to represent the handwriting data and the Canvas HTML attribute to draw the traces in the screen.

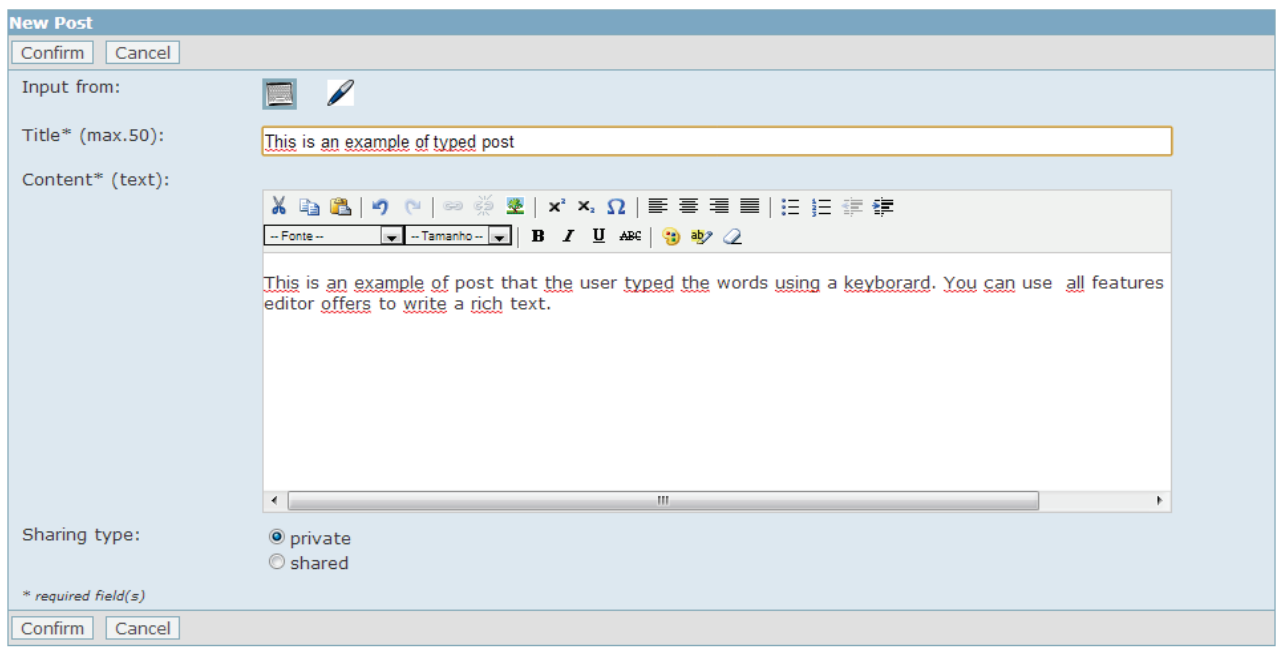

(a)

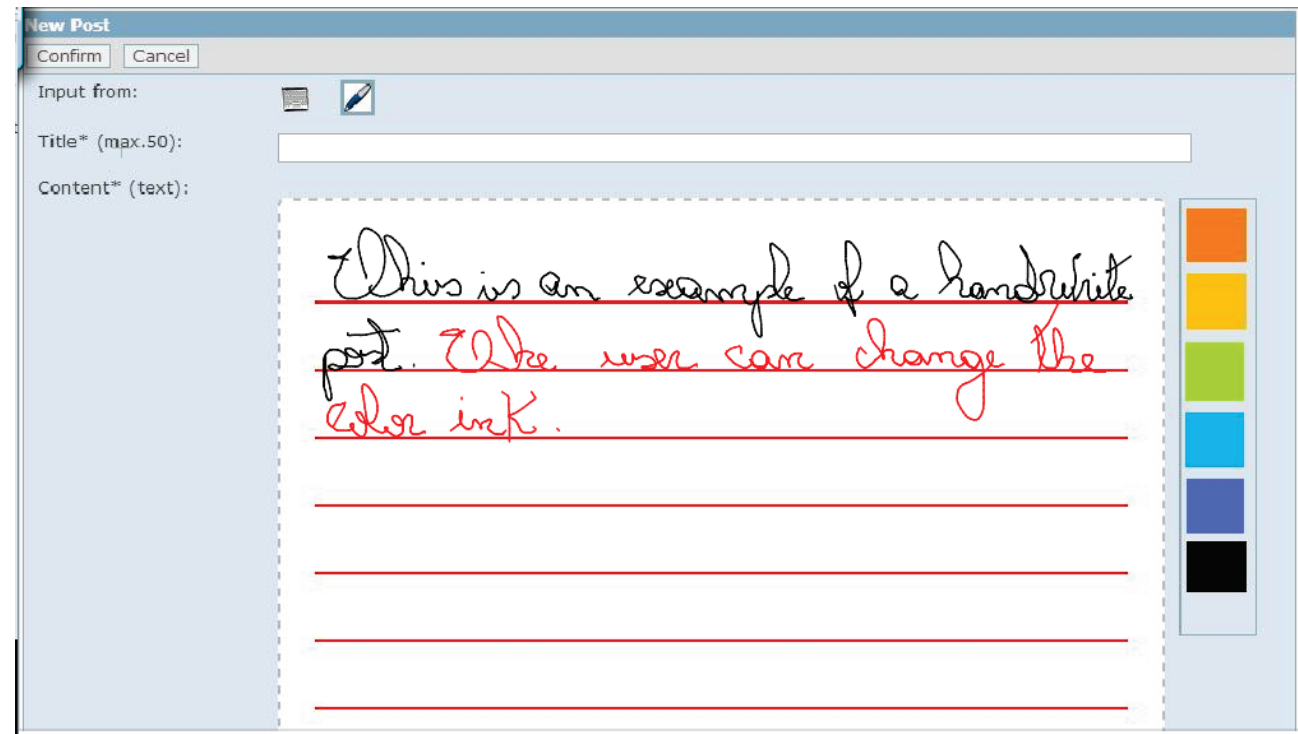

(b)

Figure 6: New post composite page to (a) type the message using keyboard and (b) handwrite the message using a pen.

To post a new message, the user can choose, selecting the icon on "input from:" field, to type the text using a keyboard (Figure 6a) or to handwrite a post, selecting the Pen option in the New Post page (Figure 6b). When the user chooses post a handwriting post, the browser will hidden the text editor and show the InkEditor, where the user will use a pen to handwriting. When the user touches the InkEditor within the pen and draw a trace, the InkController, an InkEditor component, it will listen the user actions, getting the dots that compose the trace. Each dot is recorded and a line connecting the preceding point to the new point is drawn in the canvas until the user releases the pen. After the pen release, the InkController will generate the InkML's trace node for the new trace. The user can draw how many traces she wants, all them will be stored and will 
compose the InkML file. When finalize to handwrite the post, the user will click in the Confirm button, and the generated InkML file will be sent to the server to be stored.

The pen input data is received by the InkController, who transform each point of the trace into coordinate points following InkML format. The user can choose the trace's color and the width selecting the buttons options in the right side. When the user points out and presses the pen into a color or width button, the next traces will have the brush attribute set to look likes the selected options.

The InkRenderer, another InkEditor component, draws the traces of the handwrite posts in the user screen, following the posts display order (Figure 7). InkRenderer's code, the electronic ink data in InkML format and the HTML page are sent to the client over the HTTP protocol (Figure 8). After all the data and code arrived in the client, the InkRenderer reads the InkML data resident in the canvas' data-inkml attribute, and draw the electronic ink for each trace, taking account the ink formatting. The InkRenderer was developed using the InkML JavaScript Library.

Some changes were need in the server to distinguish the textual content from the typewriting content and show the correct editor in the post view. The changes are done in the presentation component; the other components were not changed.

It is possible too handwrite comments and post them: the process is similar to the described process above.

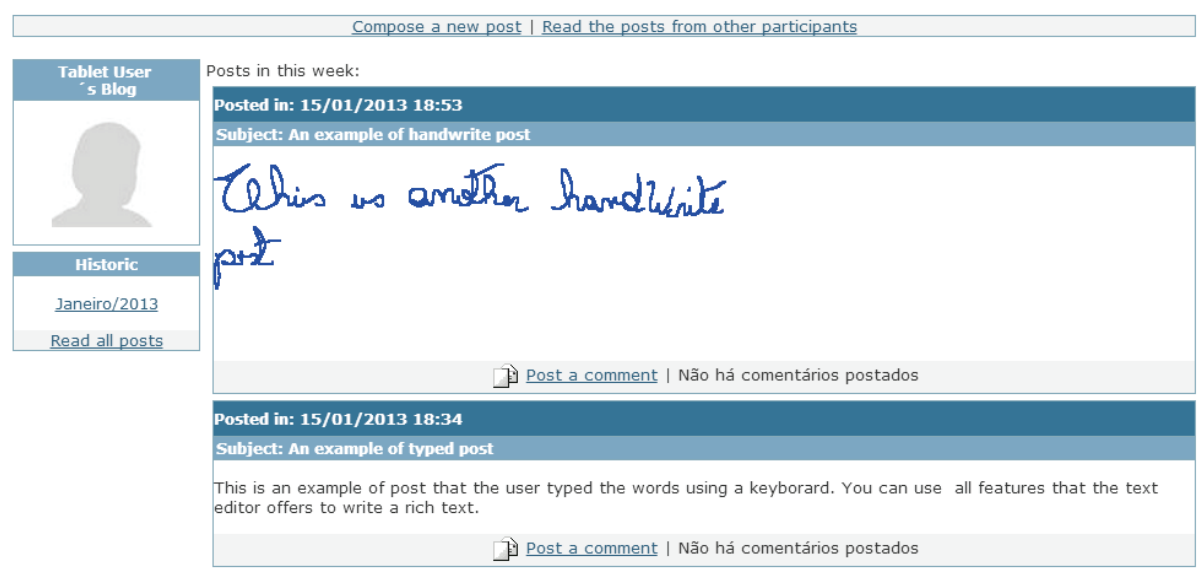

Figure 7: The user's posts page.

To test the InkBlog we used a HP TouchSmart TX2-1040br, a $2.2 \mathrm{GHz}$ dual-core processor computer with 3 GB RAM and a 12" touchscreen with Windows Vista operating system and with Windows 8 operating system. This model has the design similar to HP laptops but it is equipped with the described hardware for Tablet PC, for our purposes, a pen sensitive screen. Google Chrome browser version 22.0.1229.94m and Mozilla Firefox version 15.0.1 were used to navigate through the InkBlog and demonstrated good performance in both browsers. 


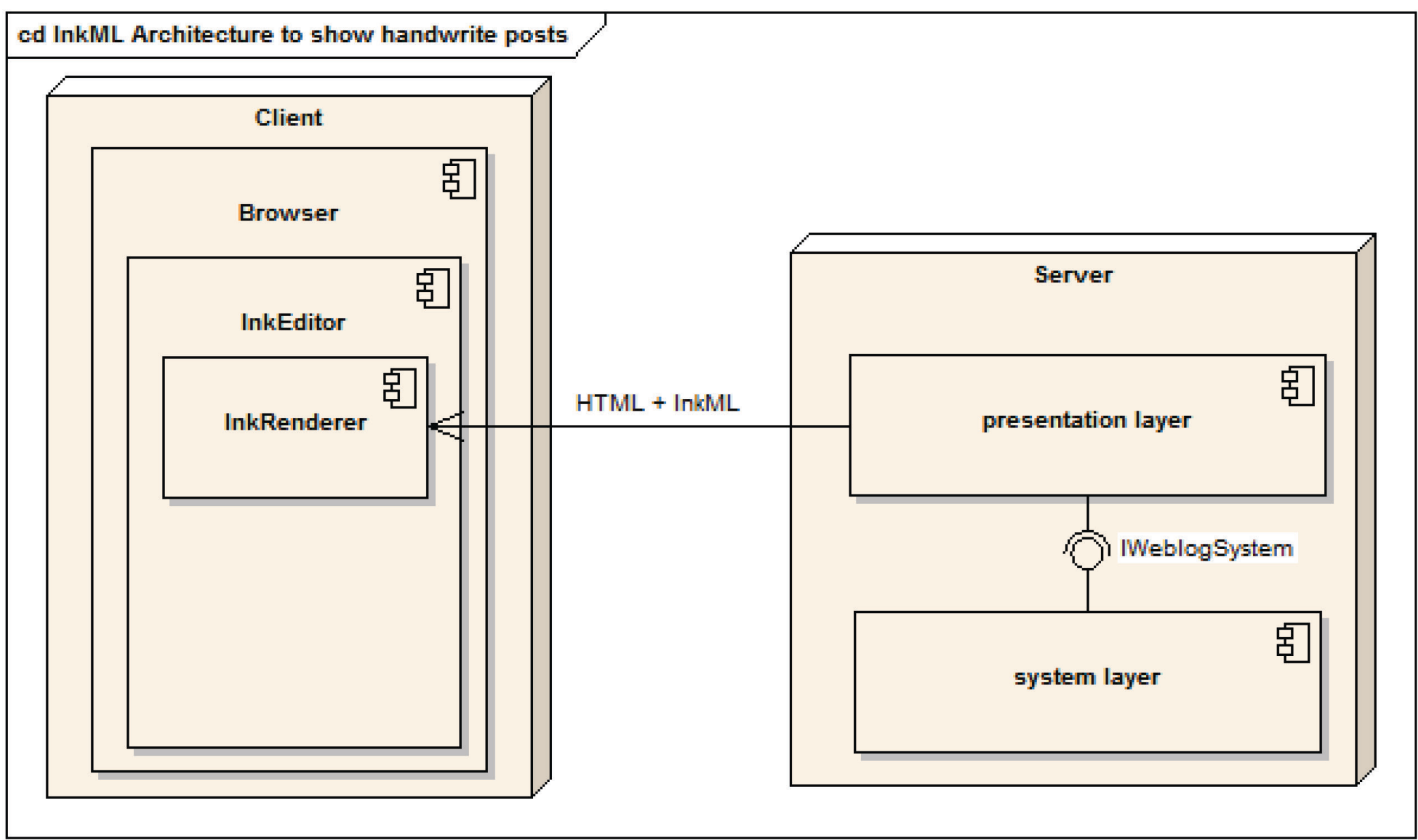

Figure 8: InkBlog Tool Components used to render a handwritten or sketched post.

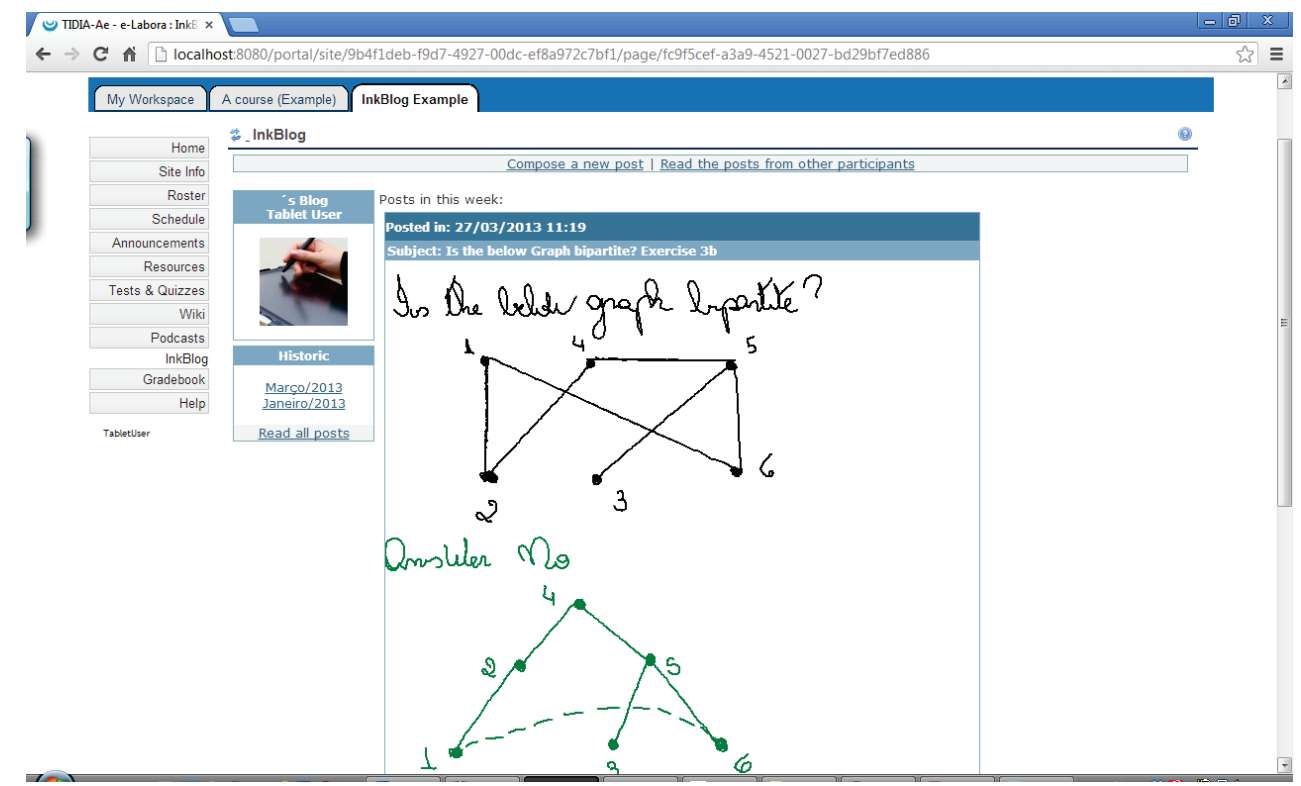

Figure 9: Using InkBlog to share a solution for an exercise about Graph Theory rendered by Chrome Browser. 


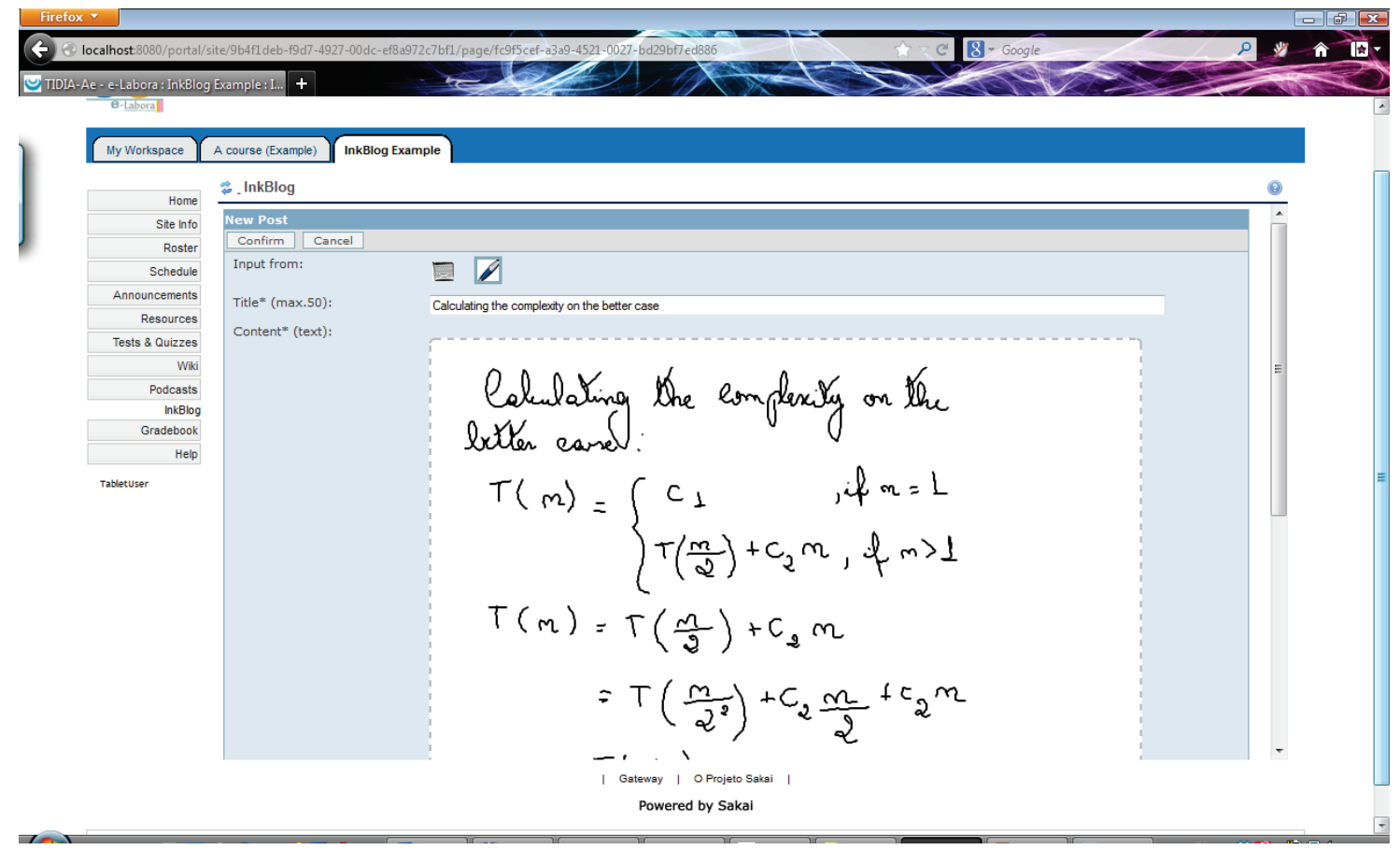

Figure 10: Using InkBlog to handwrite a reasoning to prove the better case of an algorithm in Computer Theory course rendered by Mozilla Firefox.

Using the InkBlog is possible a better support to disciplines like Graph Theory and Computer Theory. Without the InkBlog, the user needs to use paper and pencil to resolve an exercise and use specific hardware, such scanner, to digitalize the solution. Or the user needs to use a special application to draw a graph. In both solutions, the user posts the picture as an attached file in weblog post. Using the InkBlog the user can sketch the graph direct on the weblog tool through direct manipulation (Figure 9). Figure 10 shows the use InkBlog to handwrite a reasoning to prove the best case for an algorithm.

We tested the InkBlog in iPhone and Android devices (Figure 11a and 11b) using the stock browser in each device. Both devices display correct the posts, but due the platform does not distinguish between touch and stylus press, it is not possible to handwrite a post in these smartphones; both devices recognize the input as page scrolling. 


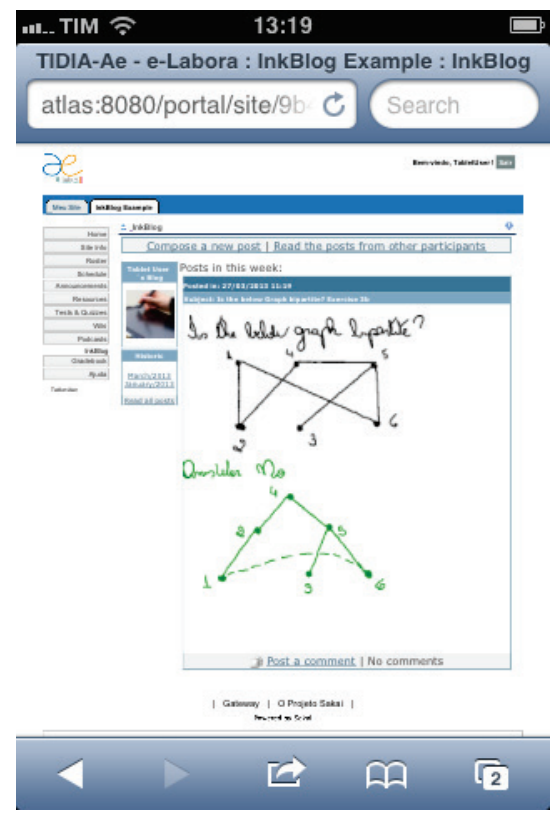

(a)

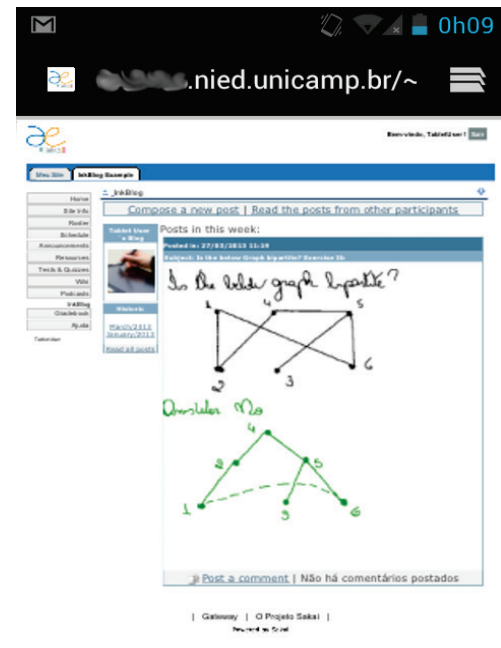

(b)

Figure 11: InkBlog rendered by stock browser on (a) iPhone and (b) Android based-device.

\section{Conclusion and Future Works}

Blog software is a communication and collaborative tool disposed in Web that aims to promote the sharing of messages among participants, and some of them are used to educational purposes, called EduBlogs. Blog can be used in many ways in classes (Ray, 2006) and it is one of the available tools in e-Learning environments, such as Weblog in Ae environment. Weblog tools use a text editor to allow users typing rich texts without HTML skill, but when the user interact with a pen she needs to typing each letter, so the usability, most specific, the efficiency decreases and making boring the writing task. Another problem is the difficult to draw sketches using the mouse. These usability problems were deal by many researches before in other contexts, e.g., when the user needs to write mathematic formulae or draw a diagram. The studied researches got the solution on pen-based computing. These researches developed solution to be installed on the computer and studied in the classroom, concluding that pen-based computing may enhance the Education in classroom. How to improve the e-Learning environment to get advantages of the Pen-based computing and enhanced the Education in distance learning? One solution is, when the user access the environment using a pen-based device, allow the user does handwriting posts and draws sketches to do her activities. We improve the Ae's Weblog with components to generate and manipulate electronic ink, calling this new tool as InkBlog.

In the InkBlog development, we chose well-defined and promising technologies, such as W3C InkML and HTML5, allowing to codify a light electronic ink editor for Web pages, the InkEditor. Some modifications are done in the Weblog for distinguish the correct editor to be displayed in the new post composite page and display handwriting posts and comments. We think allowing the Web application to manipulate the electronic ink we are powering the application with the best that the pen can offer. Using the InkBlog, users can handwriting and sketches posts and comments, powering the blog usages in areas like mathematics, architecture, fashion and music. But we need to validate this insight with some studies. 
InkBlog: A Pen-Based Blog Tool for e-Learning Environments

For future works, we will increase the InkEditor functionalities, such as ink selection, copy and paste features. Another future work is implements gesture to trigger functionalities by the integration with the environment with a gesture recognizer, and study the gesture's draw for each function. And the integration with a handwriting recognizer to recognize the word and allow a better integration with another environment tools, such search tool. Another feature to be implemented is use a post or a document as background, allowing teachers or other student to do annotation over a post.

\section{Acknowledgment}

The authors thank the CAPES and CNPq for financial support and for FAPESP through TIDIAAe Project (n. 05/60572-1), which provided the equipment.

\section{References}

Anderson, R., Anderson, R., Davis, P., Linnell, N., Prince, C., Razmov, V., et al. (2007). Classroom presenter: Enhancing interactive education with digital ink. Computer, 40(9), 56-61. doi:10.1109/MC.2007.307

Backon, J. (2006). Student minds and pen technologies: A wonderful pedagogical marriage. In D. A. Berque, J. C. Prey, \& R. H. Reed (Eds), The impact of pen-based technology on education: Vignettes, evaluations, and future directions (pp.1-11). West Lafayette, IN: Purdue University Press.

Beder, D. M., Casagrande, L., \& Rubira, C. (2004). Proposta de Arquitetura de Software para o Projeto TIDIA-Ae [TIDIA-Ae Project Software Architecture Proposal], Internal Document, TIDIA-Ae Project, São Paulo, Brazil. Retrieved January 25, 2012.

Beder, D. M., da Silva, A. C., Otsuka, J. L., da Silva, C. G., \& da Rocha, H. V. (2007, July). A case study of the development of e-learning systems following a component-based layered architecture. Proceedings of the $7^{\text {th }}$ IEEE International Conference on Advanced Learning Technologies, Niigata, Japan, 2125. doi: 10.1109/ICALT.2007.4

Benlloch, J., Buendía, F., \& Cano, J. (2009, July). Tablet PC-based learning approach on a first-year computer engineering course. Proceedings of the $9^{\text {th }}$ IEEE International Conference on Advanced Learning Technologies, Riga, Latvia, 86-87. doi: 10.1109/ICALT.2009.155

Berjon, R., Leithead, T., Navara, E. D., O'Connor, E., \& Pfeiffer, S. (2012, December). HTML5 - A vocabulary and associated APIs for HTML and XHTML W3C candidate recommendation. Retrieved March 25, 2013 from http://www.w3.org/TR/html5/

Berque, D., Bonebright, T., \& Whitesell, M (2004, March). Using pen-based computers across the computer science curriculum. Proceedings of the $35^{\text {th }}$ SIGCSE Technical Symposium on Computer Science Education, Norfolk, USA, 61-65. doi: 10.1145/1028174.971324.

Chee, Y., Franke, K., Froumentin, M., Madhvanath, S., Magaña, J., Pakosz, G., et al. (2011, September). Ink markup language (InkML) W3C recommendation. Retrieved March 25, 2013 from http://www.w3.org/TR/InkML/.

da Silva, A. C., Buchdid, S. B., dos Santos, D. T., \& da Rocha, H. V. (2006, November). A process to implement the user interface improved by struts and tiles. Proceedings of the III Workshop TIDIA FAPESP, São Paulo, Brazil. Retrieved March 25, 2013 from http://www2.icmc.usp.br/ francisco/works/IIITidia workshop.pdf.

da Silva, A. C., \& da Rocha, H. V. (2012, February) Experiences in use Tablet PC to support student's activities: Five years of an exploratory study. Proceedings of $4^{\text {th }}$ International Conference on Mobile, Hybrid, and On-line Learning, Valencia, Spain, 38-43. Retrieved March 25, 2013 from http://www.thinkmind.org/index.php?view=article\&articleid=elml_2012_2_30_50076

da Silva, A. C., Freire, F. M. P., \& da Rocha, H. V. (2013, February) Identifying cross-platform and crossmodality interaction problems in e-learning environments. Proceedings of $6^{\text {th }}$ International Conference 
on Advances in Computer- Human Interactions, Nice, France, 243-249. Retrieved March 25, 2013 from http://www.thinkmind.org/index.php?view=article\&articleid=achi_2013 9 $50 \quad 20417$

Florea, A. M., \& Radu, S. (2007, May). Enhancing pen-based experiences with the use of concept maps. Proceedings of $1^{\text {st }}$ International Workshop on Pen-Based Learning Technologies, Catania, Italy, 1-6. doi: 10.1109/PLT.2007.10

Labahn, G., Lank, E., MacLean, S., Marzouk, M. S., \& Tausky. D. (2008, September). MathBrush: A system for doing math on pen-based devices. Proceedings of the $8^{\text {th }}$ IAPR International Workshop on Document Analysis Systems, Nara, Japan, 599-606. doi: 10.1109/DAS.2008.21

McCormick, D. (2007, May). Interactive whiteboards in the classroom: A primary teacher's perspective. Proceedings of $1^{\text {st }}$ International Workshop on Pen-Based Learning Technologies, Catania, Italy, 1-4. doi: 10.1109/PLT.2007.12

O'Reilly, T. (2005). What Is Web 2.0 - Design patterns and business models for the next generation of software. Retrieved March 25, 2013 from http://www.oreillynet.com/pub/a/oreilly/tim/news/2005/09/30/what-is-web-20.html

Pargas, R., Cooper, M., Williams, C., \& Bryfczynski, S. (2007, May). OrganicPad: A tablet PC based interactivity tool for organic chemistry. Proceedings of $1^{\text {st }}$ International Workshop on Pen-Based Learning Technologies, Catania, Italy, 1-4. doi: 10.1109/PLT.2007.4

Ray, J. (2006). Welcome to the blogosphere: The educational use of blogs. Kappa delta pi record, p. 175177.

Safran, C., Helic, D., \& Gütl, C. (2007, September). E-Learning practices and Web 2.0. Proceedings of International Conference on Interactive Collaborative Learning, Villach, Austria. Retrieved March 25, 2013 from http://www.iicm.tugraz.at/iicm_papers/ICL2007_csafran_final.pdf . doi: 10.1.1.161.8553

\section{Biographies}

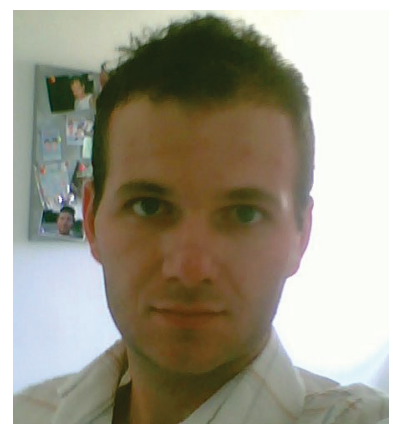

MSc. André Constantino da Silva is Professor on Institute Federal of São Paulo (IFSP), Campus Hortolândia, and he is a post graduate student in Institute of Computing (IC) of State University of Campinas (UNICAMP). His topics of interest include e-Learning, m-Learning, mobility, multimodalities, educational software and educational games development.

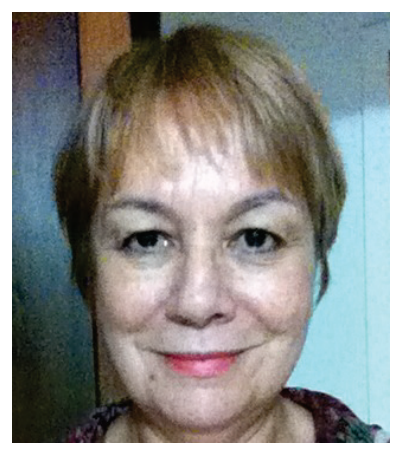

Dr. Heloísa Vieira da Rocha is Professor in Institute of Computing (IC) and researcher at the Nucleus of Informatics Applied on Education (NIED) of State University of Campinas (UNICAMP). She lectured in the areas of artificial intelligence, human-computer interaction and informatics applied on education at both undergraduate and postgraduate levels. Her main topic of interest is the junction of the Information Technologies in Education and Human-Computer Interfaces areas. 